\title{
Complications and in-hospital mortality in trauma patients treated in intensive care units in the United States, 2013
}

Meghan $\operatorname{Prin}^{1^{*}}$ and Guohua Li, $\mathrm{i}^{1,2}$

\begin{abstract}
Background: Traumatic injury is a leading cause of morbidity and mortality worldwide, but epidemiologic data about trauma patients who require intensive care unit (ICU) admission are scant. This study aimed to describe the annual incidence of ICU admission for adult trauma patients, including an assessment of risk factors for hospital complications and mortality in this population.

Methods: This was a retrospective study of adults hospitalized at Level 1 and Level 2 trauma centers after trauma and recorded in the National Trauma Data Bank in 2013. Multiple logistic regression analyses were performed to determine predictors of hospital complications and hospital mortality for those who required ICU admission.

Results: There were an estimated total of 1.03 million ICU admissions for trauma at Level 1 and Level 2 trauma centers in the United States in 2013, yielding an annual incidence of 3.3 per 1000 population. The annual incidence was highest in men (4.6 versus 1.9 per 100,000 for women), those aged 80 years or older (7.8 versus 3.6-4.3 per 100,000 in other age groups), and residents in the Western US Census region (3.9 versus 2.7 to 3.6 per 100,000 in other regions). The most common complications in patients admitted to the ICU were pneumonia (10.9\%), urinary tract infection (4.7\%), and acute respiratory distress syndrome (4.4\%). Hospital mortality was significantly higher for ICU patients who developed one or more complications (16.9\% versus $10.7 \%$ for those who did not develop any complications, $p<0.001$ ).
\end{abstract}

Conclusions: Admission to the ICU after traumatic injury is common, and almost a quarter of these patients experience hospital complications. Hospital complications are associated with significantly increased risk of mortality.

Keywords: Trauma, Hospitalization, Intensive care unit, Critical care, Complications

\section{Background}

Trauma is a major cause of morbidity and mortality in the United States. In 2013 it was the leading cause of death for people ages 35-44, and the fourth leading cause of death for the whole population (Murphy et al. 2016). Trauma includes intentional and unintentional injury from motor vehicle crashes, penetrating or blunt violence, falls, firearms, poisoning, and burns.

\footnotetext{
*Correspondence: mp3052@cumc.columbia.edu

This paper was presented in part as a poster at the 2016 annual meeting of the International Anesthesia Research Society

${ }^{1}$ Department of Anesthesiology \& Critical Care, Columbia University College of Physicians and Surgeons, 622 West 168th Street, PH 505, New York, NY 10032, USA

Full list of author information is available at the end of the article
}

Pre-hospital systems have been studied extensively to optimize the initial care of trauma patients (Williams et al. 2013; McQueen et al. 2015; McNeill and Bryden 2013; Ringburg et al. 2009; Wilson et al. 2015; National Institute for Health and Care Excellence 2016), but there is a shortage of data describing the clinical course of patients admitted to the intensive care unit (ICU) after traumatic injury. The aim of this study was to describe the clinical characteristics of adult patients admitted to the ICU after traumatic injury, including an assessment of the risk factors for hospital complications and hospital mortality in this population. 


\section{Methods}

This was a population-based, multicenter retrospective study of adult patients admitted to the ICU at Level 1 and Level 2 trauma centers after traumatic injury in 2013, using the National Trauma Data Bank (NTDB) National Sample Program. The NTDB is the largest registry of trauma data in the United States, and the National Sample Program includes data from a nationally representative sample of 100 hospitals with Level 1 or Level 2 American College of Surgery (ACS) Trauma designation. The NTDB National Sample Program data are collected prospectively by trained data abstractors at contributing hospitals, and validated centrally before pooling. Steps taken to ensure the validity of the data include the use of a data dictionary, data collection tutorials, and electronic validation of incomplete or inconsistent data. Inclusion and exclusion criteria vary between contributing hospitals. All patients were followed until hospital discharge. The National Sample Program uses a stratified sampling design, with 16 strata based on United States Census regions (Northeast, Midwest, South, and West), level of trauma care designation (ACS Levels 1 and 2), and NTDB reporting status (NTDB-contributors, NTDB-non-contributors). The final weights for hospitals are also adjusted by Emergency Room monthly volume.

Data collected as part of the National Sample Program include general patient demographics, pre-hospital emergency medical services, trauma severity scores (Injury Severity Score (ISS) (Baker et al. 1974)), injury class (e.g., blunt versus penetrating), intention (assault, self-harm, unintentional, other), Emergency Room vital signs (e.g., blood pressure, Glasgow Coma Scale Score (GCS) (Teasdale and Jennett 1974)), preexisting clinical diagnoses, in-hospital diagnosis codes, hospital length of stay, intensive care unit length of stay, and discharge status (mortality, discharge destination). Patients were included for analysis if they were 18 years or older and were admitted to the hospital. Patients were excluded if they were discharged from or died in the Emergency Room. Patients with primary burn injuries were also excluded, because Injury Severity Scores are not validated in this population and major burn injuries are frequently cared for at designated burn centers rather than trauma centers (Pruitt et al. 2012).

We first assessed transitions of care by summarizing the locations of patients after hospital admission from the Emergency Room. We were unable to assess the temporal flow of patient transitions during the hospitalization. We were also unable to account for or exclude readmissions, and patients may have been admitted more than once during the sampling period. We then summarized the national incidence rates of ICU admission with $95 \%$ confidence intervals (CI) based on United States 2013 population census data by age, gender, race, injury type, and census region (Appendix, Table 5) (United States Census Bureau 2013).

We divided all admissions into two groups: patients admitted to the ICU during the hospital course and patients not admitted to the ICU during the hospital course. We defined those who were admitted to the ICU as patients who were admitted to ICU at any time during the index hospitalization, not necessarily those admitted directly to the ICU from the Emergency Room. We summarized the general demographics (e.g., age, gender), clinical scores (e.g., Glasgow Coma Scale, Injury Severity Score) injury types (e.g., blunt, penetrating, other) and the presence of hypotension on admission (systolic blood pressure $<90 \mathrm{mmHg}$ ), which has been demonstrated as a prognostic factor in trauma patients (Parks et al. 2006). We summarized the proportion of patients who received mechanical ventilation. We assessed the prevalence of preexisting comorbidities, which were identified using codes collected and reported within the dataset for each patient (Appendix, Table 6). Preexisting comorbidities included coronary artery disease, congestive heart failure, diabetes mellitus, cerebrovascular accident, peripheral vascular disease, pulmonary disease, chronic kidney disease (including stages 1-5 based on the National Kidney Foundation practice guidelines (Levey et al. 2003)), alcoholism, and a current smoking history. Hospital length of stay and ICU length of stay were summarized using calendar days.

We identified those who were diagnosed with hospital complications using codes collected and reported within the dataset for each patient (Appendix, Table 7). Hospital complications included acute kidney injury, acute respiratory distress syndrome (ARDS), cardiac arrests, cerebrovascular accidents, decubitus ulcer, deep vein thrombosis, alcohol or drug withdrawal, myocardial infarction, pneumonia, pulmonary embolism, unplanned intubation, urinary tract infection, and sepsis. The frequency and types of complications were reported for all patients, and for patients admitted to the ICU, complications were also reported by injury mechanism. Patients may have had more than one complication during the hospitalization. Bivariate analyses were conducted to assess the relationship between patient factors and the development of hospital complications using the $\chi^{2}$ and $t$ test, as appropriate.

Multiple logistic regression analyses were performed to assess factors associated with the development of hospital complications and hospital mortality. Based on the results of Thompson et al. in creating the Mortality Risk for Trauma Comorbidity Index (Thompson et al. 2010) and the recommendation for rigorous risk-adjusted analysis of trauma mortality by Haider et al.(2012), the multivariable logistic models for hospital complications 
and hospital mortality included variables that assessed the mechanism of injury (e.g., blunt, penetrating), the physiologic severity (e.g., presence of hypotension on admission, head injury with severity $\geq 4$ on Abbreviated Injury Scale (AIS)), anatomic severity (e.g., Injury Severity Score (ISS)), age, and gender, as well as preexisting comorbidities.

Statistical anlysis was performed using Stata 12.1. We used the Stata survey procedures to account for the sampling design and sampling weights to account for differential probability of selection between strata. Weighted frequencies and proportions for each group were calculated on the basis of the relative weights for patients in each facility within the sample. Continuous variables are presented as medians with interquartile range (IQR). Missing data were rare and less than $5 \%$ for all variables included in the analysis. The study was reviewed and approved by the New York PresbyterianColumbia University Medical Center Institutional Review Board.

\section{Results}

The NTDB 2013 National Sample Program included 2,104,210 weighted records of hospital admission for traumatic injury at Level 1 and Level 2 trauma centers in 2013, and 1,028,817 (48.9 \%) included ICU admission during the index hospitalization. The majority (61.3\%) of these patients were treated in ACS Level 1 trauma hospitals. Patients were admitted from the Emergency Room to various units in the hospital, including 711,731 (33.8\%) admitted directly to the ICU (Fig. 1). The national incidence of adult ICU admission after trauma was 3.3 per 1000 (95\% CI 3.2-3.3). The incidence was highest amongst those over 80 years of age (7.8 per 1000 (95\% CI, 7.7-8.0)) (Table 1).

Male patients made up $69.4 \%$ of the ICU population, and the median age for all patients was 47 years (IQR 30-63). The majority (88.5\%) of patients were admitted to the ICU after blunt trauma, and the majority of injuries were unintentional $(85.6 \%)$. The most commonly injured body regions were the head $(39.3 \%)$ and extremities $(25.0 \%)$. The most common pre-existing comorbidities were alcoholism (13.2\%), current smoking status (17.3\%) and diabetes mellitus (10.8\%).

The development of hospital course complications was more common amongst patients admitted to the ICU than amongst patients hospitalized without ICU admission $(22.6$ versus $2.8 \%, p<0.001)$. Amongst patients admitted to the ICU the median number of complications was 1 (IQR 1-2, range 1-7). Patients who developed hospital complications were older, had more comorbidities, and more severe injuries than patients who did not develop complications (Table 2). The most common hospital complications amongst ICU patients were pneumonia (10.9 \%), urinary tract infection (4.7\%), and ARDS (4.4\%) (Table 3). Factors which conferred the highest odds ratio for hospital complications in patients admitted to the ICU were mechanical ventilation (OR 6.7 (95\% CI, 6.4-7.1) $p<0.001$ ), preexisting pulmonary disease (OR 4.7 (95\% CI, 2.6-8.4), $p<0.001$ ), and Injury Severity Score $\geq 16$ (OR 4.0 (95 \% CI, 3.6-4.4), $p<0.001$ ) (Table 4). Details on the distribution of hospital course complications stratified by mechanism of injury are available in the Additional file 1: Table S1.

Hospital mortality for patients admitted to the ICU who had hospital course complications was significantly higher than those admitted to the ICU who did not develop hospital course complications (16.9\% versus $10.7 \%, p<0.001)$. Factors which increased the odds of hospital mortality in patients admitted to the ICU included age over 80 years (OR 15.9 (95\% CI, 14.117.9), $p<0.001)$, mechanical ventilation (OR $7.7(95 \%$ CI, 7.0-8.5), $p<0.001$ ), Injury Severity Score $\geq 16$ (OR 7.3 (95 \% CI, 5.9-8.9), $p<0.001$ ), Glasgow Coma Scale Score between 3 and 8 (OR 6.6 (95\% CI, 6.1-7.1), $p<$ $0.001)$, and hospital complications including in-hospital

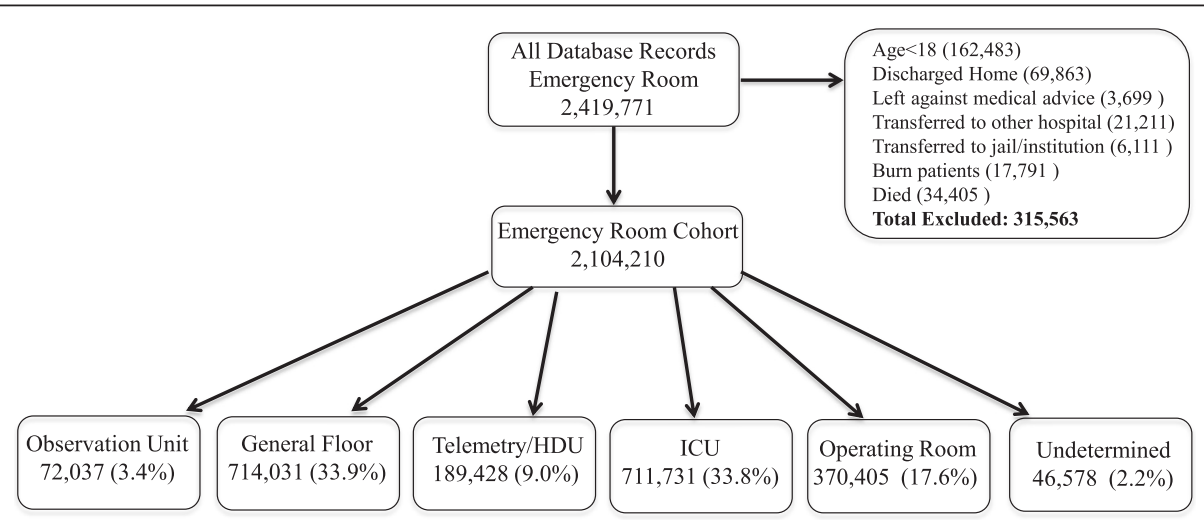

Fig. 1 Patient flows from Emergency Room. *Numbers do not add up exactly due to rounding of weighted estimates. **Does not include all patients admitted to ICU, as temporal flow of admissions not included in dataset 
Table 1 National Incidence of Intensive Care Unit Admissions after Traumatic Injury, National Trauma Data Bank, 2013

\begin{tabular}{|c|c|}
\hline & $\begin{array}{l}\text { Admissions to ICU after Trauma } \\
\text { (95\% Confidence Interval) }\end{array}$ \\
\hline Total & $3.3(3.2-3.3)$ \\
\hline \multicolumn{2}{|l|}{ Gender } \\
\hline Male & $4.6(4.6-4.6)$ \\
\hline Female & $1.9(1.9-1.9)$ \\
\hline \multicolumn{2}{|l|}{ Age, years } \\
\hline 18-39 & $4.1(4.1-4.2)$ \\
\hline $40-59$ & $3.6(3.6-3.7)$ \\
\hline $60-79$ & $4.3(4.2-4.3)$ \\
\hline$\geq 80$ & $7.8(7.7-8.0)$ \\
\hline \multicolumn{2}{|l|}{ Race $^{a}$} \\
\hline White & $2.9(2.9-2.9)$ \\
\hline Black & $3.1(3.0-3.2)$ \\
\hline \multicolumn{2}{|l|}{ Injury Class } \\
\hline Blunt & $2.9(2.8-2.9)$ \\
\hline Penetrating & $0.3(0.2-0.3)$ \\
\hline Other ${ }^{b}$ & $0.1(0.1-0.1)$ \\
\hline \multicolumn{2}{|l|}{ Intention } \\
\hline Assault & $0.4(0.4-0.4)$ \\
\hline Self-Harm & $0.1(0.1-0.1)$ \\
\hline Unintentional & $2.8(2.8-2.8)$ \\
\hline \multicolumn{2}{|l|}{ US Census Region } \\
\hline Northeast & $2.7(2.7-2.8)$ \\
\hline South & $2.9(2.8-2.9)$ \\
\hline Midwest & $3.6(3.6-3.7)$ \\
\hline West & $3.9(3.8-3.9)$ \\
\hline
\end{tabular}

${ }^{a}$ Other races (e.g., Native Americans, Asian-Americans, Native Hawaiians) not stratified for analysis because precise stratified information on these sub-categories was not available in the dataset

${ }^{b}$ Other injuries includes environmental injuries (e.g., animal attack), drownings, overdoses or toxic ingestions, suffocation, exertional injuries, and unspecified injuries

cardiac arrest (OR 9.5 (95 \% CI, 7.3-12.5), $p<0.001$ ). Each hospital complication increased the odds ratio for hospital mortality by $2.3((95 \% \mathrm{CI}, 1.8-2.8) p<0.001)$ (Table 4).

\section{Discussion}

This study describes the characteristics and outcomes for adult patients admitted to the ICU at Level 1 and Level 2 trauma hospitals after traumatic injury in the United States. We found that almost half of patients hospitalized after trauma were admitted to the ICU. This population was primarily composed of young males with blunt unintentional traumatic injuries. Hospital complications developed in almost a quarter $(22.6 \%)$ of patients who required ICU admission and were associated with a higher severity of injury (median ISS 26 (IQR 17$34)$ ). Although hospital mortality for patients admitted to the ICU (10.7\%) was not high compared to other ICU cohorts in the US, hospital mortality amongst those with hospital course complications (16.9\%) was significantly higher and similar to that of ICU populations nationwide (Lilly et al. 2011).

There is scant epidemiological literature describing patients who require critical care services after trauma in the United States. Epidemiological investigations of trauma patients admitted to the ICU have been conducted in other high-income countries (Curtis et al. 2012), developing countries (Chalya et al. 2011; Adenekan 2009) and in military settings (Brown et al. 2011), but these studies lack generalizability to the United States because of variations in the availability and structure of pre-hospital systems and different ICU bed availability. Although descriptive studies have been conducted in the United States, these studies are often single-center (Ong et al. 2009) or focused on very specific subsets of patients (Brown et al. 2011; Majidi et al. 2014; Nishijima et al. 2013; Lustenberger et al. 2011; Recinos et al. 2009; Sangthong et al. 2006), which also limits generalizability. One recent multicenter study described the case mix, complications, and outcomes of 11,064 patients admitted to ICUs after trauma, and found that hospital complications were associated with age, gender, and traumatic CNS injury (Mondello et al. 2014). The rigor of our study is attributable to the large number of patients from hospitals across the country, the prospective validated data collection process, and the representative nature of the data.

Although ICU admission for traumatic injury, at least for some period of observation, is common practice in many centers (Kaufman et al. 2016), regional triage criteria and the actual utilization of ICU-level care (e.g., mechanical ventilation) are unclear. The severity of illness for patients admitted to the ICU in this study was only moderately high (median ISS 17, IQR $10-27)$. ICU admission for observation-only may theoretically result in unnecessarily high healthcare costs (Wunsch et al. 2008), exposure of patients to ICU-related complications (e.g., nosocomial infections (Grundmann et al. 2005) and medical errors during transfers of care (Bell et al. 2011)), and denial of ICU beds to other patients. Similarly, ICU admission for patients with extremely high expected mortality may be considered futile, and may also result in high healthcare costs and delayed ICU admission for other patients (Huynh et al. 2014). Admission decisions are often subjective, and for these reasons it is important to clarify the optimal use of ICU resources. This study may serve as a first step to informing ICU triage decisions for trauma patients. For example, these data demonstrate a higher severity of injury amongst patients with hospital course complications who were admitted 
Table 2 Descriptive statistics of hospitalized adults admitted to the ICU versus not admitted to the ICU after trauma including those with hospital course complications, National Trauma Data Bank, 2013

\begin{tabular}{|c|c|c|c|c|c|c|}
\hline & \multicolumn{3}{|c|}{ Admitted to ICU, weighted frequency (\%) } & \multicolumn{3}{|c|}{ Not admitted to ICU, weighted frequency (\%) } \\
\hline & Total & With Complications & $p$-value & Total & With Complications & $p$-value ${ }^{b}$ \\
\hline Total & $1,028,817(100)$ & $232,618(22.6)$ & $<0.001$ & $1,075,393(100)$ & $30,350(2.8)$ & $<0.001$ \\
\hline Male & $712,904(69.4)$ & $172,967(74.5)$ & $<0.001$ & $681,396(63.5)$ & $20,934(69.1)$ & $<0.001$ \\
\hline Age, years ${ }^{a}$ & $47(30-63)$ & $50(33-63)$ & $<0.001$ & $47(31-64)$ & $56(42-72)$ & $<0.001$ \\
\hline ACS Trauma Designation & & & $<0.001$ & & & $<0.001$ \\
\hline Level 1 & $630,679(61.3)$ & $152,942(65.7)$ & & $600,481(55.8)$ & $19,634(64.7)$ & \\
\hline Level 2 & $398,138(38.7)$ & $79,676(34.3)$ & & $474,912(44.2)$ & $10,716(35.3)$ & \\
\hline Number of complications & NA & $1(1-2)$ & & NA & $1(1-1)$ & $<0.001$ \\
\hline Injury Class & & & 0.253 & & & $<0.001$ \\
\hline Blunt & $905,149(88.5)$ & 206,317 (89.1) & & $949,370(88.3)$ & $27,543(90.8)$ & \\
\hline Penetrating & $89,461(8.7)$ & $18,693(8.1)$ & & $87,510(8.1)$ & $1838(6.1)$ & \\
\hline Other ${ }^{c}$ & $28,239(2.8)$ & $6626(2.9)$ & & $38,024(3.5)$ & $942(3.1)$ & \\
\hline Intention & & & $<0.001$ & & & $<0.001$ \\
\hline Assault & $115,665(11.3)$ & $22,026(9.5)$ & & $139,440(12.9)$ & $2669(8.8)$ & \\
\hline Self-harm & $23,860(2.3)$ & $5787(2.5)$ & & $10.989(1.0)$ & $373(1.2)$ & \\
\hline Unintentional & $875,604(85.6)$ & $201.794(87.1)$ & & $919,374(85.5)$ & $27,191(89.7)$ & \\
\hline Undetermined & $7720(0.8)$ & $2028(0.9)$ & & $5102(0.5)$ & $90(0.3)$ & \\
\hline$I S S^{a}$ & $17(10-27)$ & $26(17-34)$ & $<0.001$ & $9(5-12)$ & $10(5-17)$ & $<0.001$ \\
\hline GCS Score & $15(10-15)$ & $13(3-15)$ & $<0.001$ & $15(15-15)$ & $15(14-15)$ & $<0.001$ \\
\hline Hypotension on Admission (SBP < 90 mmHg) & $75,195(7.4)$ & $27,310(12.1)$ & $<0.001$ & $18,049(1.7)$ & $2148(7.1)$ & $<0.001$ \\
\hline Site of Injury ${ }^{d}$ & & & $<0.001$ & & & $<0.001$ \\
\hline Head & $402,462(39.3)$ & $80,917(34.9)$ & & $307,578(28.7)$ & $7575(25.0)$ & \\
\hline Thorax & $150,598(14.7)$ & $38,725(16.7)$ & & $114,816(10.7)$ & $3692(12.2)$ & \\
\hline Spine & $118,202(11.5)$ & $30,944(13.3)$ & & $92,583(8.6)$ & $2368(7.8)$ & \\
\hline Abdomen & $75,112(7.3)$ & $20,155(8.7)$ & & $41,600(3.9)$ & $2018(6.7)$ & \\
\hline Extremity & $256,043(25.0)$ & $57,498(24.8)$ & & $483,327(45.1)$ & $14,056(46.4)$ & \\
\hline Other & $21,583(2.1)$ & $3598(1.6)$ & & $31,794(2.9)$ & $582(1.9)$ & \\
\hline \multicolumn{7}{|l|}{ Comorbidities } \\
\hline Alcoholism & $135,774(13.2)$ & $41,254(17.7)$ & $<0.001$ & $105,255(9.8)$ & 8066 (26.6) & $<0.001$ \\
\hline Cerebrovascular Accident & $21,504(2.1)$ & $6718(2.9)$ & $<0.001$ & $22,046(2.1)$ & $1989(6.6)$ & 0.603 \\
\hline Chronic Kidney Disease & $9808(1.0)$ & $3877(1.7)$ & $<0.001$ & $9878(0.9)$ & $1551(5.1)$ & 0.489 \\
\hline Congestive Heart Failure & $29,195(2.8)$ & $8206(3.5)$ & $<0.001$ & $32,259(2.9)$ & $1881(3.5)$ & 0.067 \\
\hline Coronary Artery Disease & $15,056(1.5)$ & $4910(2.1)$ & $<0.001$ & $15,327(1.4)$ & $2368(7.8)$ & 0.463 \\
\hline Current Smoker & $177,724(17.3)$ & $40,623(17.5)$ & 0.425 & 207,069 (19.3) & $7184(23.7)$ & $<0.001$ \\
\hline Diabetes Mellitus & $111,095(10.8)$ & $29,573(12.7)$ & $<0.001$ & $116,138(10.8)$ & $5905(19.5)$ & 0.993 \\
\hline Peripheral Vascular Disease & $2815(0.3)$ & $904(0.4)$ & 0.002 & $2925(0.3)$ & $344(1.1)$ & 0.944 \\
\hline Pulmonary Disease & $1317(0.1)$ & $717(0.3)$ & $<0.001$ & $1021(0.1)$ & $197(0.6)$ & 0.060 \\
\hline Mechanical ventilation & $517,950(50.3)$ & $193,722(83.3)$ & $<0.001$ & $30,641(2.8)$ & $2825(9.3)$ & $<0.001$ \\
\hline Intensive Care Unit LOS'a, days & $4(2-8)$ & $12(6-21)$ & $<0.001$ & NA & NA & $<0.001$ \\
\hline Hospital LOSa, days & $4(2-8)$ & $12(6-21)$ & $<0.001$ & $3(2-6)$ & $7(3-11)$ & $<0.001$ \\
\hline Hospital mortality & $109,580(10.7)$ & 39,204 (16.9) & $<0.001$ & $15,716(1.5)$ & $4991(16.4)$ & $<0.001$ \\
\hline
\end{tabular}

ISS Injury Severity Score, GCS Glasgow Coma Scale, ACS American College of Surgery, SBP systolic blood pressure, LOS length of stay

${ }^{\mathrm{a}}$ Continuous variables presented as sample median (Interquartile Range)

${ }^{\mathrm{b}}$ This value reflects analysis between those admitted to ICU who had hospital complications and those not admitted to ICU who had hospital complications 'Other injuries includes environmental injuries (e.g., animal attack), drownings, overdoses or toxic ingestions, suffocation, exertional injuries, and unspecified injuries

${ }^{\mathrm{d} H e a d}$ includes Abbreviated Injury Scale scores for Head, Face, and Neck. Extremity includes all four extremities 
Table 3 Hospitalized patients admitted to the ICU versus not admitted to the ICU after trauma, with hospital course complications by type ${ }^{\text {a }}$, National Trauma Data Bank, 2013*

\begin{tabular}{lll}
\hline & $\begin{array}{l}\text { Admitted to ICU, } \\
\text { weighted frequency (\%) }\end{array}$ & $\begin{array}{l}\text { Not Admitted to ICU, } \\
\text { weighted frequency (\%) }\end{array}$ \\
\hline Acute Kidney Injury & $20,593(2.0)$ & $3192(0.3)$ \\
ARDS & $45,280(4.4)$ & $1570(0.1)$ \\
Cardiac Arrest & $21,145(2.1)$ & $4559(0.4)$ \\
Cerebrovascular Accident & $21,504(2.1)$ & $22,046(2.1)$ \\
Decubitus Ulcer & $23,160(2.3)$ & $1390(0.1)$ \\
Deep Vein Thrombosis & $43,283(4.2)$ & $4155(0.4)$ \\
Drug/Alcohol Withdrawal & $23,061(2.2)$ & $7291(0.7)$ \\
Myocardial Infarction & $5771(0.6)$ & $994(0.1)$ \\
Pneumonia & $112,221(10.9)$ & $6300(0.6)$ \\
Pulmonary Embolism & $12,759(1.2)$ & $1968(0.2)$ \\
Unplanned Intubation & $25,586(2.5)$ & $267(0.0)$ \\
Urinary Tract Infection & $48,695(4.7)$ & $10,587(0.9)$ \\
Sepsis & $15,476(1.5)$ & $478(0.0)$ \\
Total & $232,618(22.6)$ & $30,350(2.8)$
\end{tabular}

ARDS acute respiratory distress syndrome

*Differences between those admitted to ICU and those not admitted to ICU different in all categories, significant at $p<0.001$

a Patients may have developed more than one complication

to the ICU (median ISS 26, IQR 17-34). Although we cannot establish whether hospital course complications occurred before or after ICU admission, hospital course complications may be one clinical factor utilized to determine whether some proportion of patients may be safely treated in other hospital areas, such as intermediate care units, without adversely affecting outcomes.

Additionally, these data demonstrate that $50.3 \%$ of trauma patients admitted to the ICU receive mechanical ventilation, while up to $9.3 \%$ of trauma patients admitted to other hospital areas also require mechanical ventilation. With the exception of patients intubated for airway protection (i.e., central nervous system trauma, airway hemorrhage, penetrating chest trauma), alternatives to mechanical ventilation may be explored for some patients to reduce the prevalence of associated complications and mortality. For example, non-invasive pressure support ventilation has demonstrated a mortality benefit in adult trauma patients (Roberts et al. 2014; Chiumello et al. 2013). The reasons behind the relatively high provision of mechanical ventilation in non-ICU settings deserves further attention.

The hospital complication rate amongst patients admitted to the ICU was high (22.6 \%). With increasing scrutiny on quality of care and recent linking of complication rates to reimbursement (Sipkoff 2008), healthcare systems nationwide are searching for ways to reduce in-hospital complications. An important target of future research should include clarifying the time course of hospital complications in hospitalized trauma patients, so as to better identify modifiable risk factors. Preexisting comorbidities were also common in the ICU cohort, especially alcoholism, smoking, and diabetes, despite a generally young population. Notably, these three common comorbidities were not strong predictors of hospital complications and were not associated with an increased risk of hospital mortality. Although the mechanism underlying this association is beyond the scope of this study, these findings are consistent with the results of a single-center study evaluating smoking and trauma outcomes (Ferro et al. 2010). The comorbidities most strongly associated with hospital complications and mortality (pulmonary disease, peripheral vascular disease, and chronic kidney disease) were rare in the cohort. This type of information may help guide triage decisions and future study design.

An important limitation of these data is the lack of temporal association between ICU admission and the development of hospital complications. We do not suggest that hospital complications lead to ICU admission, or vice versa. This important data would greatly enhance the ability to draw clinical conclusions from this study. This study also includes only those patients admitted to American College of Surgery Level 1 and Level 2 designated trauma centers. Despite well-developed trauma triage systems in the United States, some proportion of patients will be treated at Level III or IV centers, or non-trauma centers, and this study does not include these patients. Another limitation is the lack of detailed clinical data about intra-hospital patient transfers, staffing, rapid response teams, and ICU organization. Finally, although the sampling population of hospitals in the National Sample Program is intended to be nationally representative, this likely increases the heterogeneity of ICU and hospital organization within the cohort. Organizational hospital-level factors have been shown to affect outcomes (Sakr et al. 2015) and these limitations limit the generalizability and interpretation of these results.

\section{Conclusions}

ICU admission after traumatic injury in adults is common, and almost a quarter of these patients will develop hospital course complications. Hospital complications are associated with significantly higher hospital mortality for ICU patients, and more detailed clinical data is necessary to identify modifiable risk factors. Describing the characteristics and hospital course of patients admitted to the ICU after traumatic injury is an important first step to clarifying the needs of this population. 
Table 4 Adjusted odds ratios, with $95 \%$ Confidence Intervals (Cl), of factors associated with hospital course complications and hospital mortality in trauma patients admitted to the ICU, National Trauma Data Bank, 2013

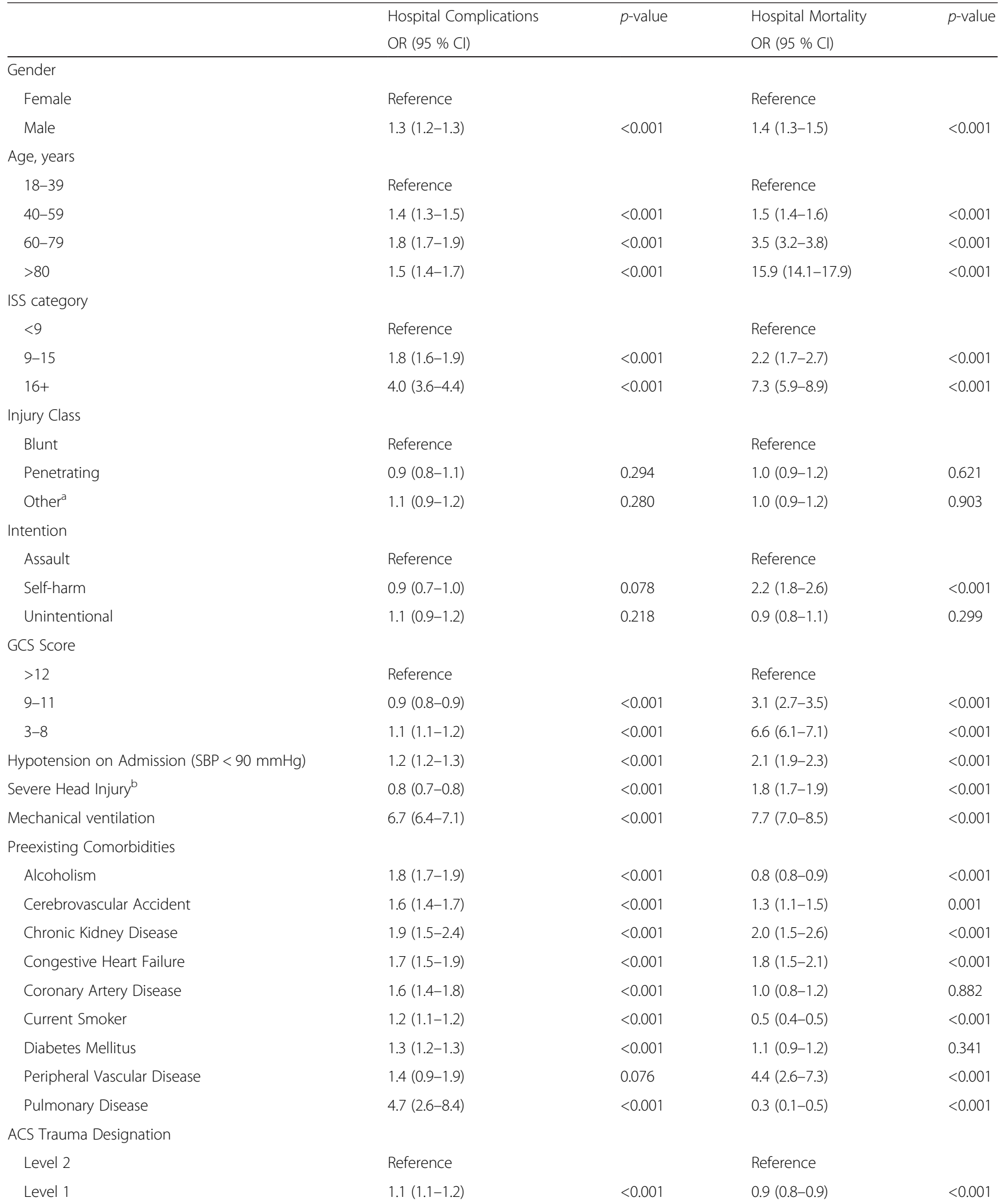


Table 4 Adjusted odds ratios, with $95 \%$ Confidence Intervals (Cl), of factors associated with hospital course complications and hospital mortality in trauma patients admitted to the ICU, National Trauma Data Bank, 2013 (Continued)

\begin{tabular}{|c|c|c|c|c|}
\hline$\overline{\text { Developed Hospital Complications (Yes/No })^{c}}$ & - & - & $0.7(0.6-0.8)$ & $<0.001$ \\
\hline Number of Complications (range $0-7$ ) & & & $2.3(1.8-2.8)$ & $<0.001$ \\
\hline Acute Kidney Injury & - & - & $0.9(0.6-1.2)$ & 0.376 \\
\hline ARDS & - & - & $0.6(0.5-0.7)$ & $<0.001$ \\
\hline Cardiac Arrest & - & - & $9.5(7.3-12.5)$ & $<0.001$ \\
\hline Cerebrovascular Accident & - & - & $2.1(1.5-2.9)$ & $<0.001$ \\
\hline Decubitus Ulcer & - & - & $0.2(0.2-0.3)$ & $<0.001$ \\
\hline Deep Vein Thrombosis & - & - & $0.1(0.1-0.2)$ & $<0.001$ \\
\hline Drug/Alcohol Withdrawal & - & - & $0.2(0.1-0.3)$ & $<0.001$ \\
\hline Myocardial Infarction & - & - & $0.9(0.6-1.3)$ & 0.443 \\
\hline Pneumonia & - & - & $0.2(0.2-0.3)$ & $<0.001$ \\
\hline Pulmonary Embolism & - & - & $0.3(0.2-0.4)$ & $<0.001$ \\
\hline Unplanned Intubation & - & - & $0.5(0.4-0.6)$ & $<0.001$ \\
\hline Urinary Tract Infection & - & - & $0.5(0.4-0.5)$ & $<0.001$ \\
\hline Sepsis & - & - & $2.3(1.9-2.9)$ & $<0.001$ \\
\hline
\end{tabular}

Cl confidence interval, ISS Injury Severity Score, GCS Glasgow Coma Scale, ACS American College of Surgery, SBP systolic blood pressure, ARDS acute respiratory distress syndrome

${ }^{a}$ Other injuries includes environmental injuries (e.g., animal attack), drownings, overdoses or toxic ingestions, suffocation, exertional injuries, and unspecified injuries

${ }^{\mathrm{b}}$ Severe Head injury includes Abbreviated Injury Scale scores for Head, Face, and Neck with severity greater than or equal to 4

'Reference is no complications

\section{Appendix}

Table 5 United States 2013 national population, stratified by gender, age-group, race, and census region (United States Census Bureau 2013) ${ }^{a}$

\begin{tabular}{ll}
\hline United States population, total & $316,128,839$ \\
Gender & \\
Male & $155,651,602$ \\
Female & $160,477,237$ \\
Age, years & \\
$18-39$ & $95,307,000$ \\
$40-59$ & $84,983,000$ \\
$60-79$ & $49,910,000$ \\
$>80$ & $10,988,000$ \\
Race & \\
White & $245,499,216$ \\
Black & $41,623,897$ \\
Other & \\
Census Region & $21,264,998$ \\
Northeast & \\
Midwest & $55,943,073$ \\
South & $67,547,890$ \\
West & $118,383,453$ \\
\hline anited States 2013 population data as of July 1, 2013, accessed through \\
https://www.census.gov/population/age/data/2013comp.html on May 9, 2016 \\
bOther includes Native Americans, Asian-Americans, Native Hawaiians
\end{tabular}

Table 6 National Trauma Data Bank National Sample Program, 2013 data codes of pre-existing comorbidities utilized in analysis

\begin{tabular}{|c|c|}
\hline $\begin{array}{l}\text { Pre-existing } \\
\text { comorbidities }\end{array}$ & Source in dataset \\
\hline $\begin{array}{l}\text { Coronary Artery } \\
\text { Disease }^{\mathrm{a}}\end{array}$ & $\begin{array}{l}\text { NTDB comorbidity codes } 16,17 \\
\text { ICD9 codes } 414.01,440.9,414.00,414.4,414.3 \\
414.02\end{array}$ \\
\hline $\begin{array}{l}\text { Congestive Heart } \\
\text { Failure }\end{array}$ & NTDB comorbidity code 7 \\
\hline Diabetes Mellitus & NTDB comorbidity code 11 \\
\hline $\begin{array}{l}\text { Cerebrovascular } \\
\text { Accident }\end{array}$ & NTDB comorbidity code 10 \\
\hline $\begin{array}{l}\text { Peripheral Vascular } \\
\text { Disease }\end{array}$ & NTDB comorbidity code 18 \\
\hline Pulmonary Disease & $\begin{array}{l}\text { ICD9 codes 490.0, 490, 491.0, 491.1, 491.2, 491.20, } \\
491.22,491.8,491.9,492.0,492.8,493,493.0,493.1, \\
\text { 493.2, 494.0, 493.1, 495.0, 495.1, 495.2, 495.3, 495.4, } \\
\text { 495.5, 495.6, 495.7, 495.8, 495.9, 496.0 }\end{array}$ \\
\hline $\begin{array}{l}\text { Chronic Kidney } \\
\text { Disease }\end{array}$ & $\begin{array}{l}\text { ICD9 codes 585.1, 585.2, 585.3, 585.4, 585.5, } \\
585.6,585.9\end{array}$ \\
\hline Alcoholism & NTDB comorbidity code 2 \\
\hline Current Smoker & NTDB comorbidity code 8 \\
\hline
\end{tabular}

${ }^{a}$ Because the NTDB dataset used multiple comorbidity codes to indicate coronary artery disease (e.g., history of a myocardial infarction and history of angina), additional ICD9 codes were queried to ensure no cases were missing 
Table 7 National Trauma Data Bank National Sample Program, 2013 data codes of hospital complications utilized in analysis

\begin{tabular}{|c|c|}
\hline Complications & Source in dataset \\
\hline Acute Kidney Injury & $\begin{array}{l}\text { NTDB complication code } 4 \\
\text { ICD9 584.5-584.9, 588.0-588.9, 585.89, 585.9, 593.9, } 958.5\end{array}$ \\
\hline ARDS & $\begin{array}{l}\text { NTDB complication code } 5 \\
\text { ICD9 518.5, } 518.82\end{array}$ \\
\hline Cardiac Arrest & $\begin{array}{l}\text { NTDB complication code } 8 \\
\text { ICD9 } 427.5 \text { in conjunction with } 99.60-99.69,427.5 \text { with } 37.91 ; \text { v12.53 }\end{array}$ \\
\hline Cerebrovascular Accident & $\begin{array}{l}\text { NTDB complication code } 22 \\
\text { ICD9 } 434.01,434.11,434.91,433.01-433.91,997.02\end{array}$ \\
\hline Decubitus Ulcer & $\begin{array}{l}\text { NTDB complication code } 11 \\
707.00 \text { through } 707.09\end{array}$ \\
\hline Deep Vein Thrombosis & $\begin{array}{l}\text { NTDB complication code } 14 \\
\text { ICD9 } 451.0,451.11,451.19,451.2,451.81-451.84,451.89,451.9,453.40,459.10-459.19,997.2,999.2\end{array}$ \\
\hline Alcohol/Drug Withdrawal & $\begin{array}{l}\text { NTDB complication code } 13 \\
\text { ICD9 291.0, 291.3, 291.81, } 292.0\end{array}$ \\
\hline Myocardial Infarction & $\begin{array}{l}\text { NTDB complication code } 18 \\
\text { IC9 } 414.8,412\end{array}$ \\
\hline Pneumonia & $\begin{array}{l}\text { NTDB complication code } 20 \\
\text { IC9 480.0-480.9, 481, 482.0-482.3, 482.30-483.39, 482.40-482.49, 482.81-482.89, 482.9, 483.0-483.8, } \\
484.1-484.8,485,486,997.31\end{array}$ \\
\hline Pulmonary Embolism & $\begin{array}{l}\text { NTDB complication code } 21 \\
\text { ICD9 } 415.11,415.12,415.19,416.2\end{array}$ \\
\hline Unplanned intubation & $\begin{array}{l}\text { NTDB complication code } 25 \\
\text { "Patient requires placement of an endotracheal tube and mechanical or assisted ventilation because } \\
\text { of the onset of respiratory or cardiac failure manifested by severe respiratory distres, hypoxia, } \\
\text { hypercarbia, or respiratory acidosis. In patients who were intubated in the field or Emergency } \\
\text { Department, or those intubated for surgery, unplanned intubation occurs if they require } \\
\text { reintubation > } 24 \text { h after extubation." NTDB User Manual } 2013\end{array}$ \\
\hline Urinary Tract Infection & $\begin{array}{l}\text { NTDB complication code } 27 \\
\text { ICD9 } 595.0-595.9 \text { or } 599.0\end{array}$ \\
\hline Sepsis & $\begin{array}{l}\text { NTDB complication code } 32 \\
\text { ICD9 } 785.52,995.92\end{array}$ \\
\hline
\end{tabular}

\section{Additional file}

Additional file 1: Table S1. Weighted frequency and percentage of patients admitted to the ICU with hospital course complications by type, stratified by mechanism of injury, National Trauma Data Bank, 2013. (DOC $43 \mathrm{~kb}$ )

\section{Abbreviations}

ACS, American College of Surgery; AIS, Abbreviated Injury Scale; ARDS, acute respiratory distress syndrome; $\mathrm{Cl}$, confidence intervals; GCS, Glasgow Coma Scale; ICU, intensive care unit; IQR, interquartile range; ISS, Injury Severity Score; LOS, length of stay; NTDB, National Trauma Data Bank; SBP, systolic blood pressure

\section{Funding}

This study was supported in part by the National Center for Injury Prevention and Control, of the Centers for Disease Control and Prevention (Grant 1 R49 CE002096). The contents of the manuscript are solely the responsibility of the authors and do not necessarily reflect the official views of the funding agency.

\section{Authors' contributions}

MP helped to conceive the project, contributed to project design, performed data collection and analysis, and helped write the manuscript. GL helped to conceive the project, contributed to project design, and helped to write the manuscript. Both authors read and approved the final manuscript.

\section{Competing interests}

The authors declare that they have no competing interests.

\section{Declarations}

The NTDB remains the full and exclusive copyrighted property of the American College of Surgeons. The American College of Surgeons is not responsible for any claims arising from works based on the original Data, Text, Tables, or Figures.

\section{Author details}

${ }^{1}$ Department of Anesthesiology \& Critical Care, Columbia University College of Physicians and Surgeons, 622 West 168th Street, PH 505, New York, NY 10032, USA. ²Department of Epidemiology, Columbia University Mailman School of Public Health, New York, NY, USA.

Received: 14 June 2016 Accepted: 2 August 2016

Published online: 04 August 2016

\section{References}

Adenekan ATFA. Trauma admissions to the ICU of a tertiary hospital in a low resource setting. Af J Anaesth Intensive Care. 2009;9:5-7.

Baker SP, O'Neill B, Haddon Jr W, Long WB. The injury severity score: a method for describing patients with multiple injuries and evaluating emergency care. J Trauma. 1974;14:187-96.

Bell CM, Brener SS, Gunraj N, Huo C, Bierman AS, Scales DC, Bajcar J, Zwarenstein M, Urbach DR. Association of ICU or hospital admission with unintentional discontinuation of medications for chronic diseases. JAMA. 2011;306:840-7. 
Brown LM, Kallet RH, Matthay MA, Dicker RA. The influence of race on the development of acute lung injury in trauma patients. Am J Surg. 2011;201: 486-91.

Chalya PL, Gilyoma JM, Dass RM, McHembe MD, Matasha M, Mabula JB, Mbelenge N, Mahalu W. Trauma admissions to the intensive care unit at a reference hospital in Northwestern Tanzania. Scand J Trauma Resusc Emerg Med. 2011;19:61.

Chiumello D, Coppola S, Froio S, Gregoretti C, Consonni D. Noninvasive ventilation in chest trauma: systematic review and meta-analysis. Intensive Care Med. 2013;39:1171-80.

Curtis KA, Mitchell RJ, Chong SS, Balogh ZJ, Reed DJ, Clark PT, D'Amours S, Black DA, Langcake ME, Taylor CB, McDougall P, Cameron PA. Injury trends and mortality in adult patients with major trauma in New South Wales. Med $J$ Aust. 2012;197:233-7.

Ferro TN, Goslar PW, Romanovsky AA, Petersen SR. Smoking in trauma patients: the effects on the incidence of sepsis, respiratory failure, organ failure, and mortality. J Trauma. 2010;69:308-12.

Grundmann H, Barwolff S, Tami A, Behnke M, Schwab F, Geffers C, Halle E, Gobel UB, Schiller R, Jonas D, Klare I, Weist K, Witte W, Beck-Beilecke K, Schumacher M, Ruden $\mathrm{H}$, Gastmeier P. How many infections are caused by patient-to-patient transmission in intensive care units? Crit Care Med. 2005;33:946-51.

Haider AH, Saleem T, Leow JJ, Villegas CV, Kisat M, Schneider EB, Haut ER, Stevens KA, Cornwell 3rd EE, MacKenzie EJ, Efron DT. Influence of the National Trauma Data Bank on the study of trauma outcomes: is it time to set research best practices to further enhance its impact? J Am Coll Surg. 2012:214:756-68

Huynh TN, Kleerup EC, Raj PP, Wenger NS. The opportunity cost of futile treatment in the ICU*. Crit Care Med. 2014:42:1977-82.

Kaufman EJWD, Martin ND, Pascual JL, Reilly PM, Holena, DN. Variation in intensive care unit utilization and mortality after blunt splenic injury. J Surg Res. 2016. Epub.

Levey AS, Coresh J, Balk E, Kausz AT, Levin A, Steffes MW, Hogg RJ, Perrone RD, Lau J, Eknoyan G, National Kidney F. National Kidney Foundation practice guidelines for chronic kidney disease: evaluation, classification, and stratification. Ann Intern Med. 2003;139:137-47.

Lilly CM, Zuckerman $\mathrm{IH}$, Badawi O, Riker RR. Benchmark data from more than 240,000 adults that reflect the current practice of critical care in the United States. Chest. 2011;140:1232-42.

Lustenberger T, Inaba K, Schnuriger B, Barmparas G, Eberle BM, Lam L, Talving P, Demetriades D. Gunshot injuries in the elderly: patterns and outcomes. A national trauma databank analysis. World J Surg. 2011;35:528-34.

Majidi S, Hassan AE, Adil MM, Jadhav V, Qureshi Al. Incidence and outcome of vertebral artery dissection in trauma setting: analysis of national trauma data base. Neurocrit Care. 2014;21:253-8.

McNeill G, Bryden D. Do either early warning systems or emergency response teams improve hospital patient survival? A systematic review. Resuscitation. 2013:84:1652-67.

McQueen C, Smyth M, Fisher J, Perkins G. Does the use of dedicated dispatch criteria by Emergency Medical Services optimise appropriate allocation of advanced care resources in cases of high severity trauma? A systematic review. Injury. 2015;46:1197-206.

Mondello S, Cantrell A, Italiano D, Fodale V, Mondello P, Ang D. Complications of trauma patients admitted to the ICU in level I academic trauma centers in the United States. Biomed Res Int. 2014;2014:473419.

Murphy SL, Xu J, Kochanek KD, Bastian BA. Deaths: Final Data for 2013. Natl Vital Stat Rep. 2016;64:1-119.

National Institute for Health and Care Excellence: Clinical Guidelines. In: Major Trauma: Assessment and Initial Management. London, 2016. http://www.ncbi.nlm.nih.gov/ pubmed/26913320. Accessed 10 May 2016.

Nishijima DK, Haukoos JS, Newgard CD, Staudenmayer K, White N, Slattery D, Maxim PC, Gee CA, Hsia RY, Melnikow JA, Holmes JF. Variability of ICU use in adult patients with minor traumatic intracranial hemorrhage. Ann Emerg Med. 2013;61:509-17. e4.

Ong AW, Omert LA, Vido D, Goodman BM, Protetch J, Rodriguez A, Jeremitsky E. Characteristics and outcomes of trauma patients with ICU lengths of stay 30 days and greater: a seven-year retrospective study. Crit Care. 2009;13:R154.

Parks JK, Elliott AC, Gentilello LM, Shafi S. Systemic hypotension is a late marker of shock after trauma: a validation study of Advanced Trauma Life Support principles in a large national sample. Am J Surg. 2006;192:727-31.
Pruitt BA, Wolf SE, Mason AD. Epidemiological, demographic, and outcome characteristics of burn injury. In: Herndon DN, editor. Total burn care. 4th ed. Philadelphia: PA Elsevier; 2012. pp15-26.

Recinos G, DuBose JJ, Teixeira PG, Barmparas G, Inaba K, Plurad D, Green DJ, Demetriades $\mathrm{D}$, Belzberg $\mathrm{H}$. ACS trauma centre designation and outcomes of post-traumatic ARDS: NTDB analysis and implications for trauma quality improvement. Injury. 2009;40:856-9.

Ringburg AN, de Ronde G, Thomas SH, van Lieshout EM, Patka P, Schipper IB. Validity of helicopter emergency medical services dispatch criteria for traumatic injuries: a systematic review. Prehosp Emerg Care. 2009;13:28-36.

Roberts S, Skinner D, Biccard B, Rodseth RN. The role of non-invasive ventilation in blunt chest trauma: systematic review and meta-analysis. Eur J Trauma Emerg Surg. 2014:40:553-9.

Sakr Y, Moreira CL, Rhodes A, Ferguson ND, Kleinpell R, Pickkers P, Kuiper MA Lipman J, Vincent JL, Extended Prevalence of Infection in Intensive Care Study I. The impact of hospital and ICU organizational factors on outcome in critically ill patients: results from the Extended Prevalence of Infection in Intensive Care study. Crit Care Med. 2015;43:519-26.

Sangthong B, Demetriades D, Martin M, Salim A, Brown C, Inaba K, Rhee P, Chan L. Management and hospital outcomes of blunt renal artery injuries: analysis of 517 patients from the National Trauma Data Bank. J Am Coll Surg. 2006;203: $612-7$

Sipkoff M. Medicare's big changes. Manag Care. 2008;17:29-30. 5-6.

Teasdale G, Jennett B. Assessment of coma and impaired consciousness. A practical scale. Lancet. 1974;2:81-4.

Thompson HJ, Rivara FP, Nathens A, Wang J, Jurkovich GJ, Mackenzie EJ. Development and validation of the mortality risk for trauma comorbidity index. Ann Surg. 2010;252:370-5.

United States Census Bureau. Age and Sex Composition in the United States. vol. 2016. 2013. https://www.census.gov/population/age/data/2013comp.html. Accessed 9 May 2016

Williams T, Finn J, Fatovich D, Jacobs I. Outcomes of different health care contexts for direct transport to a trauma center versus initial secondary center care: a systematic review and meta-analysis. Prehosp Emerg Care. 2013:17:442-57.

Wilson MH, Habig K, Wright C, Hughes A, Davies G, Imray CH. Pre-hospital emergency medicine. Lancet. 2015;386:2526-34.

Wunsch H, Angus DC, Harrison DA, Collange O, Fowler R, Hoste EA, de Keizer NF, Kersten A, Linde-Zwirble WT, Sandiumenge A, Rowan KM. Variation in critical care services across North America and Western Europe. Crit Care Med. 2008; 36:2787-93. e1-9.

\section{Submit your manuscript to a SpringerOpen ${ }^{\circ}$ journal and benefit from:}

- Convenient online submission

- Rigorous peer review

- Immediate publication on acceptance

Open access: articles freely available online

- High visibility within the field

- Retaining the copyright to your article

Submit your next manuscript at $>$ springeropen.com 